\title{
RE: Validation of the brazilian version of the expanded prostate cancer index composite (EPIC) for patients submitted to radical prostatectomy
}

\author{
Enaury Alves ${ }^{1}$, Rebecca Medina ${ }^{1}$, Cássio Andreoni ${ }^{1}$ \\ ${ }^{1}$ Department of Urology, Escola Paulista de Medicina da Universidade Federal de São Paulo, EPM/ \\ UNIFESP - Sao Paulo, SP, Brazil
}

Int Braz J Urol. 2013; 39: 344-52

\section{To the editor,}

Nowadays, optimize oncologic results and minimize the negative impact of local and systemic treatments on quality of life of patients with prostate cancer guide the way the treatment of prostate cancer is carried out.

Since 2006, our group has partnered with leading authors of the most used patient-related outcomes questionnaires in prostate cancer. We have followed the international standardized translational process, cultural adaptation and pilot-test for the Brazilian version of the UCLA-PCI ${ }^{\circledR}$ and the EORTC QLQ-PR25 ${ }^{\circledR}$ (1). The projects were approved by the both Ethics Committees.

We read with interest the recently published paper regarding the Brazilian version of the EPIC ${ }^{\circledR}$ questionnaire (2). We support Alves et al. efforts in the improvement of the quality of life research in our country, with its known socio-cultural heterogeneity. There is, however, a missed step to complete the validation of the EPIC ${ }^{\circledR}$ questionnaire. The psychometrics properties are: reliability, validity and responsiveness. Reliability is important to measure score consistency, but it doesn't guarantee the validation of a questionnaire (3). Furthermore, the EPIC ${ }^{\circledR}$ and the UCLA-PCI ${ }^{\circledR}$ should be scored in association with the core instrument (Rand SF-36 ${ }^{\circledR}$ V2). The SF-36 ${ }^{\circledR}$ is copyright and the researcher must pay royalties and user fees to QualityMetry ${ }^{\circledR}$ in order to use with the PCI and EPIC.

The European Organization for Research and Treatment of Cancer, Quality of Life Group (EORTC QoL) offer the core instrument (EORTC C-30 ${ }^{\circledR}$ ), the cancer-specific module PR25 $5^{\circledR}$ and the scoring manuals free of charge for academic non-sponsored projects (http://groups.eortc.be/qol/). The PR25 ${ }^{\circledR}$ is composed by two functional scales (sexual activity and sexual functioning) and 4 symptoms scales (urinary symptoms, bowel symptoms, hormone treatment-related symptoms and incontinence aid). The sexual functioning scale is conditional on being sexually active and the incontinence aid is a conditional scale that must be answered only by patients using pads.

Using a structured interview, we report here the internal consistency of the Brazilian version of the PR25 ${ }^{\circledR}$ applied to 186 prostate cancer patients regardless if local or metastatic tumors. All patients enrolled were treated at two reference centers located in south of Brazil, with different cultural background (Santa Casa de Porto Alegre in Porto Alegre/RS and Centro de Pesquisas Oncológicas/CEPON in Florianópolis/SC). The overall internal consistency of the PR25 was measured using the Cronbach's 
alpha, and was considered good ( $\alpha=0.79)$. Three scales showed good to moderate internal consistency: urinary symptoms $(\alpha=0.86)$, sexual activity $(\alpha=0.74)$ and sexual functioning $(\alpha=0.73)$. Two did not satisfied the standardized reliability of 0.7 criteria: bowel symptoms $(\alpha=0.51)$ and hormonal treatment-related symptoms $(\alpha=0.49)$. Incontinence aid is a single item scale. In the international validation of the PR25, similar issues concerning the reliability for each subscales were reported $(4,5)$.

Nowadays, we finished the recruitment phase and validity and responsiveness properties will be soon published. We claimed for the use of validated questionnaires in urology and clinical oncology research, allowing the reported outcomes obtained by Brazilian researchers can be compared to the international literature.

\section{REFERENCES}

1. Heldwein FL, Rhoden EL, Hartmann A, Teloken C. Appropriate utilization of quality of life outcomes in prostate and bladder cancer: practical considerations for Brazilian Portuguese questionnaires. Clinics (Sao Paulo). 2009;64:487-8.

2. Alves E, Medina R, Andreoni C. Validation of the Brazilian version of the Expanded Prostate Cancer Index Composite (EPIC) for patients submitted to radical prostatectomy. Int Braz J Urol. 2013;39:344-52.

3. Heldwein FL, Sánchez-Salas RE, Sánchez-Salas R, Teloken $\mathrm{PE}$, Teloken C, Castillo 0 , et al. Health and quality of life in urology: issues in general urology and urological oncology. Arch Esp Urol. 2009;62:519-30.
4. van Andel G, Bottomley A, Fosså SD, Efficace F, Coens C Guerif $S$, et al. An international field study of the EORTC QLQ-PR25: a questionnaire for assessing the health-related quality of life of patients with prostate cancer. Eur $\mathrm{J}$ Cancer. 2008;44:2418-24.

5. Arraras JI, Villafranca E, Arias de la Vega F, Romero P, Rico M, Vila M, et al. The EORTC Quality of Life Questionnaire for patients with prostate cancer: EORTC QLQ-PR25. Validation study for Spanish patients. Clin Transl Oncol. 2009;11:160-4

Flavio L. Heldwein, Jefferson L. Traebert, MD Department of Urology, Universidade do Sul de Santa Catarina, Florianopolis, SC, Brazil Rua Altamiro Guimaraes, 360 Florianopolis, SC, 88015-510, Brazil E-mail:flavio.lobo@gmail.com

Antonio A. Hartmann, MD;

Giovani T. Pioner, MD; Claudio Teloken, MD Department of Urology, Universidade de Ciencias da Saude de Porto Alegre, Porto Alegre, RS, Brazil 